\title{
Revisão:
}

\section{Modificações físico-químicas na carne in natura bovina decorrentes da alta pressão hidrostática}

Review:

\author{
Physicochemical modifications in fresh bovine \\ meat resulting from high hydrostatic pressure
}

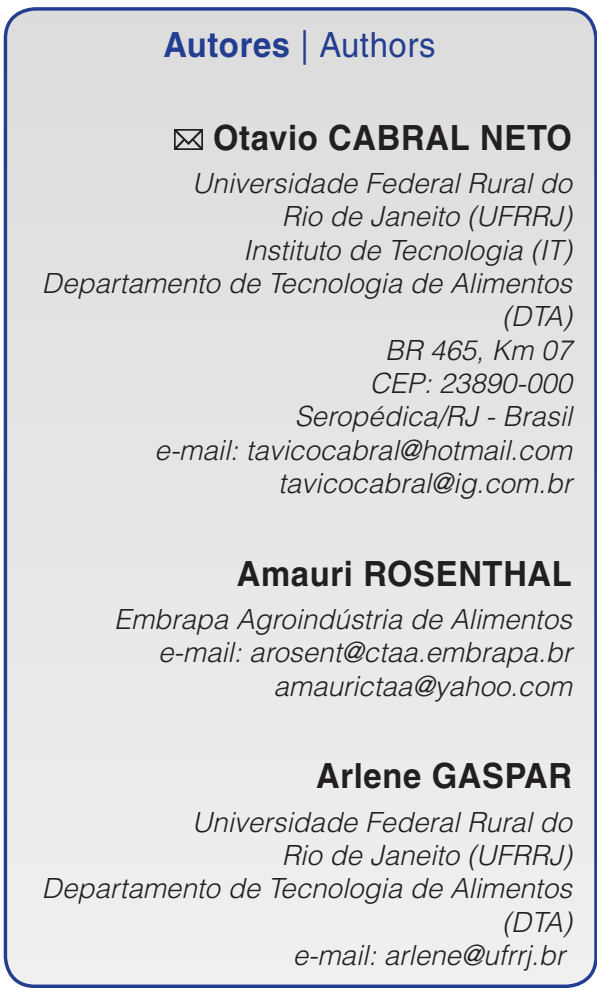

Autor Correspondente / Corresponding Author

Recebido / Received: 10/03/2010 Aprovado / Approved: 11/03/2011

\section{Resumo}

O Brasil tem se mostrado como grande potência em produção e exportação de carne, porém, abaixo de seu potencial de mercado, por abater, em sua maioria, animais zebuínos ou azebuados, os quais possuem reconhecidamente uma carne "menos macia". O atributo maciez é o principal fator de qualidade relacionado à carne para exportação; nesse sentido, são estudados e empregados métodos de amaciamento, como a maturação convencional, relacionada à ação de enzimas proteolíticas. Mais recentemente, tem sido pesquisado o processo de alta pressão hidrostática (APH), que tem se mostrado promissor para, em menor período de tempo, propiciar o amaciamento de carne e de produtos cárneos, não implicando em grande aumento da temperatura durante o processamento e, dessa forma, modificando minimamente as características originais dos produtos. Esta revisão aborda a aplicação do processo de alta pressão hidrostática sobre a carne in natura e as modificações decorrentes nas características físico-químicas, abrangendo a importância e as perspectivas de aplicação dessa tecnologia para a melhoria da qualidade do produto.

Palavras-chave: Alta pressão hidrostática; Textura; Cor; Oxidação lipídica; Maciez; Carne bovina.

\section{Summary}

Brazil is one of the top meat producers and exporters in the world, but the predominant use of zebuine cattle, which have been related to less tender meat, has limited further commercial expansion. The texture attribute of tenderness is the main factor associated with meat quality for exportation, and in this sense different treatments have been evaluated aiming at softening the meat, such as the traditional ageing process, related to the action of proteolytic enzymes. More recently high hydrostatic pressure has proved to be a promising softening treatment for fresh meat and meat products, providing an adequate texture in a shorter period without the use of high process temperatures, and thus minimally altering the original characteristics of the product. This paper aims to review the literature on the application of high hydrostatic pressure to fresh meat and discusses the effects of the process on the physical and chemical characteristics. It also discusses the importance and prospects of the application of this technology in order to improve the quality of fresh meat and meat products.

Key words: High hydrostatic pressure; Texture; Color; Lipid oxidation; Fresh meat; Bovine meat. 


\section{Introdução}

A bovinocultura de corte é uma atividade econômica explorada em todos os continentes e responde por cerca de $47 \%$ do total da produção brasileira de carnes. Destaca-se em particular por alcançar um excelente desempenho de participação no PIB brasileiro, atingindo valores superiores a $4,5 \%$ (OMC, 2007). Dados do IBGE (2008) mostram o efetivo total do rebanho bovino no Brasil em aproximadamente 170 milhões de cabeças e uma projeção de crescimento que aponta, no final do ano de 2009, para um total de 204 milhões. Tais índices colocam o País em destaque com o maior rebanho comercial do mundo.

A carne bovina é mundialmente muito consumida e, no Brasil, atinge valores superiores a $42 \mathrm{~kg} / \mathrm{hab} / \mathrm{ano}$ (IBGE, 2008). O principal destino de exportação da carne brasileira é a União Europeia, que apresenta um mercado bastante amplo, mas ao mesmo tempo muito exigente quanto ao padrão de segurança e de satisfação do consumidor, principalmente em relação às características nutricionais e sensoriais, em termos de maciez, cor, sabor e suculência do produto. Dessa forma, a competitividade da carne bovina no mercado internacional está intimamente associada à eficiência em gerenciar aspectos de qualidade e inocuidade do produto, bem como na redução de custos de perdas e refugos, na otimização de produção e processamento, e na logística de distribuição.

O mercado brasileiro é basicamente caracterizado pelo abate de bovinos zebuínos ou azebuados, cuja carne é considerada "menos macia" quando comparada com a dos bovinos taurinos. Tal aspecto deve-se principalmente às diferenças nas concentrações de algumas enzimas proteolíticas, demandando aplicação de tecnologias específicas nas etapas de criação, abate e frigorificação dessas carnes, de maneira que possam contribuir para melhoria da textura relacionada ao atributo da maciez, como no caso de abate de animais precoces.

O processamento de alta pressão vem sendo mais recentemente estudado como possível alternativa para o amaciamento de carnes, de forma a reduzir o tempo requerido para o alcance das características desejadas de textura, aumentando, por consequência, a eficiência e o rendimento do processo.

O processo já vem sendo empregado em uma série de aplicações na indústria de alimentos, notadamente para inativação de microrganismos patogênicos e deteriorantes, e de enzimas, permitindo assim o prolongamento da validade comercial dos produtos (VARDAG et al., 1995). Esse processo pode também induzir a mudanças relevantes na textura dos alimentos, resultantes de redução no volume e de mudanças no pH (WILLIANS, 1994), além de alterações ocasionadas por mudanças na conformação molecular de compostos como proteínas, abrangendo diferentes possibilidades de utilização industrial.

Solomon et al. (2006), utilizando o processo de alta pressão hidrostática (APH), observaram que este se mostrou muito efetivo na melhoria da maciez em vários cortes de carne, com resultados superiores, quando comparado ao amaciamento obtido com a maturação convencional. O processamento objetivando amaciamento acontece em fração de segundos, contribuindo assim para a redução no custo de energia, espaço e mão de obra, quando comparado a processos convencionais e a outros tratamentos envolvendo APH.

Objetivou-se neste artigo revisar os estudos sobre aplicação da tecnologia de alta pressão hidrostática, principalmente em relação às alterações físicas e químicas causadas por esta tecnologia na carne bovina in natura.

\section{Revisão bibliográfica}

\subsection{Tecnologia de alta pressão}

O processo de alta pressão aplicado a alimentos consiste basicamente em submeter os produtos a pressões hidrostáticas bastante elevadas (50 a $1000 \mathrm{MPa}$ ), bem acima daquelas normalmente empregadas nos processos mais usuais aplicados a alimentos (ZIMMERMAN e BERGMAN, 1993), como homogeneização e esterilização térmica.

Hite (1899) e Bridgman (1914) foram os pioneiros nas pesquisas usando a tecnologia de alta pressão hidrostática (APH) em alimentos, enfocando inativação de bactérias em leite. A partir dos primeiros trabalhos, estudos pontuais objetivando a aplicação da alta pressão em alimentos foram realizados, porém, devido ao avanço dos processos térmicos, a tecnologia ficou relegada a um plano secundário. Somente a partir de 1990, com pesquisas realizadas no Japão objetivando avaliação do potencial de aplicação comercial, a retomada dos estudos foi restabelecida em vários outros países, com destaque para os Estados Unidos e países europeus. Tais pesquisas resultaram em ampliação da base técnicocientífica e grande avanço tecnológico, acarretando surgimento de diversos produtos comercializados, em vários países, processados por alta pressão.

O processo de APH e a maturação são alternativas de técnicas de pós-abate para aumentar a maciez da carne. O processo de APH aplica ondas de transmissão de pressão (shockwaves) para romper fisicamente a estrutura do músculo, enquanto o amaciamento pela maturação é relacionado com a degradação proteolítica das proteínas miofibrilares (BOWKER et al., 2006). 
A pressão age sobre o produto, sem provocar alterações negativas que podem ocorrer em processos térmicos de elevada intensidade. O fluido usado no recipiente de pressão tem propriedades adiabáticas próprias e influencia a temperatura final do alimento, situando-se normalmente em níveis moderados ao longo do processo. Fluidos típicos usados em recipientes de pressão para a esterilização de alimentos incluem glicerol, água, álcool 70\%, óleos comestíveis e água/emulsões de óleos comestíveis (MEYER et al., 2000).

Dois princípios formam a base do efeito da APH: o princípio de Le Chatelier e o princípio da pressão isostática. O primeiro corresponde àquele no qual qualquer fenômeno, transição de fase, mudança de conformação molecular ou reação química, acompanhado por uma redução de volume, é favorecido pelo aumento de pressão, e vice-versa. No caso de uma reação, a pressão alterará o equilíbrio na direção do sistema de menor volume (CHEFTEL, 1995). O segundo princípio indica que a pressão é transmitida de uma forma quase e praticamente uniforme e instantânea através de uma amostra biológica, contida no vaso de pressão (BARBOSA-CÁNOVAS e RODRÍGUEZ, 2002).

Independentemente do equipamento utilizado para o processamento por APH, o sistema básico é composto por quatro componentes: recipiente de pressão, sistema gerador de pressão, dispositivo para controle da temperatura e sistema operacional. A parte mais importante é o recipiente, pois é ele que suporta toda a pressão aplicada no processo. Os recipientes são fabricados a partir de um bloco de liga de aço, com capacidade para suportar elevados níveis de pressão. O sistema gerador de pressão causa um leve aumento da temperatura do alimento associado às propriedades adiabáticas já mencionadas, sendo este um dos motivos pelo qual se faz necessário o dispositivo de controle da temperatura. A outra função deste dispositivo é a possibilidade de uso de diferentes faixas de temperatura para o processo $\left(0-100{ }^{\circ} \mathrm{C}\right)$, o qual funciona pelo bombeamento de água fria ou quente ao redor do recipiente de pressão (MERTENS e DEPLACE, 1993).

Quanto aos modos de operação, o processo de alta pressão pode ser classificado em três categorias: por batelada, semicontínuo e contínuo. O processo por batelada é o mais simples: uma quantidade de produto é pressurizada por vez. Esta pressurização pode ser direta ou indireta. No processo direto (bulk processing), o próprio alimento é o meio pressurizante. Exemplos: os alimentos líquidos, como os sucos e o leite, que são embalados após o processamento por alta pressão em sistema asséptico (FAO, 2001).

A pressurização indireta, também chamada in-container, é aquela em que existe um meio pressurizante (exemplo: água ou água/óleo), que é responsável por transferir a pressão gerada pelo gerador de pressão para o alimento; este processo é aplicado para alimentos previamente embalados. As embalagens indicadas para o processo indireto são EVOH (Ethylene-Vinyl Alcohol Copolymere) e PVOH (PolyVinyl Alcohol Copolymere), pois não sofrem deformação (HAYASHI et al., 1989). Uma vantagem deste processo é a possibilidade de utilizar o sistema para vários alimentos, sem o risco de contaminação cruzada ou a necessidade de limpeza entre um processamento e outro, pois os alimentos já foram previamente embalados.

Quando se deseja aumentar a produção do sistema por batelada, emprega-se o processo semicontínuo, no qual vários recipientes de pressão são colocados em sequência; enquanto alguns estão em pressão constante, outros estão sendo pressurizados, carregados ou descarregados, reduzindo o tempo entre os processos e permitindo recuperação de energia. No equipamento do processo semicontínuo, o pistão que gera a pressão fica livre, podendo atuar sobre vários recipientes (FDA, 2000). O processo por batelada e o semicontínuo podem ser utilizados tanto para alimentos líquidos quanto para sólidos.

O processo contínuo pode apenas ser utilizado para alimentos líquidos, pois o equipamento é composto por tubos ou recipientes de retenção que promovem um tempo de tratamento específico para o processo. Após o processamento, o alimento é acondicionado em tanques estéreis para posterior embalagem (MERTENS e DEPLACE, 1993).

No processamento isostático, o produto é embalado em garrafa ou bolsa plástica, e colocado no interior do vaso de pressão (ou recipiente), o qual é preenchido com o líquido de transferência de pressão ao produto (PELLIETIER, 2001). Experimentos demonstraram que qualquer embalagem com flexibilidade e resistência suficientes para compensar a compressão do ar no seu interior e a redução do volume do alimento (aproximadamente $12 \%$ a $400 \mathrm{MPa}$ ou até $15 \%$ a pressões acima de $500 \mathrm{MPa}$ ) (FARKAS e HOOVER, 2000) pode ser adotada sem sofrer danos (GARCIA et al., 1992). A energia mecânica de pressurização dentro do recipiente resulta em uma geração de calor moderada e temporária, denominada de calor adiabático, em que a cada $100 \mathrm{MPa}$ de elevação de pressão, a temperatura é aumentada de 3 a $6{ }^{\circ} \mathrm{C}$, dependendo do equipamento, e podendo variar conforme a natureza do produto (FARKAS e HOOVER, 2000; ROVERE, 1995; BUTZ e TAUSCHER, 2002; ANSTINE, 2003). Assim, para exemplificação, se o alimento contém uma quantidade significativa de gordura, o aumento da temperatura será mais elevado.

De forma geral, o uso de APH tem as seguintes vantagens: torna possível o processamento para conservação de alimentos à temperatura ambiente 
ou mais baixas; possibilita a uniforme transmissão de pressão sobre o alimento, independentemente da sua forma e tamanho, dispensando operações preliminares; proporciona morte microbiana sem o uso de aditivos químicos, e pode ser utilizado para o desenvolvimento de produtos com propriedades funcionais (RASTOGI et al., 2008).

As formas vegetativas dos eucariotos, tais como os fungos e leveduras, são inativadas por pressões entre 200 e 300 MPa. Bactérias Gram positivas são mais resistentes ao calor e à pressão do que as bactérias Gram negativas. Esporos de bactérias podem sobreviver em pressões acima de 1000 MPa (CHEFTEL, 1995). Segundo Paterson (2005), o tratamento à alta pressão não inativa completamente microrganismos e uma pequena proporção da população sofre injúria. Segundo o autor, a recuperação das células injuriadas depende das condições após o tratamento.

Os custos envolvidos na aquisição dos equipamentos e do processamento ainda limitam o uso dessa tecnologia, embora sua utilização tenha se mostrado crescente. Avanços têm sido realizados no desenho e na construção desses equipamentos para tornar os custos mais competitivos em relação a outros processos de conservação (SLONGO, 2008). Estima-se que o custo operacional do processo à alta pressão esteja em torno de US\$ 0,05/libra, considerando-se a depreciação dos equipamentos sendo de dez anos. No entanto, o montante de investimento considerando o custo do equipamento ainda é elevado (MEYER et al., 2000).

\subsection{Efeito da APH sobre as proteínas}

Proteínas são polímeros formados por sequência específica de aminoácidos, que sofrem arranjos dobrando-se sobre si mesmas e que, ao final, formam estruturas tridimensionais definidas, dotadas de função biológica. Esta estrutura única do processo denominado enovelamento proteico é mantida por um somatório de interações (pontes de hidrogênio, interações iônicas, interações hidrofóbicas, forças de Van Der Waals), porém altamente específicas, que se estabelecem entre diferentes grupamentos da proteína. Além dessas, existem ligações mais fortes como pontes dissulfeto, ligações covalentes, que são difíceis de serem alteradas. Quando expostas às condições de alta temperatura, pH extremo e APH, as proteínas podem desenovelar-se e perder parcialmente sua estrutura e ação. A APH age ao forçar a entrada de água no cerne proteico, resultando na quebra das interações fracas e, consequentemente, no desnovelamento proteico (CREIGHTON, 1990 apud PALMIERI, 2005).

Segundo estudos bioquímicos, pressões acima de 200 MPa geralmente causam, à temperatura ambiente, a dissociação de estruturas oligoméricas em suas subunidades, a abertura parcial, a desnaturação das estruturas monoméricas - em muitos casos, irreversíveis - e a gelatinização das proteínas, sempre que a pressão e a concentração de proteínas sejam altamente suficientes (CHEFTEL e CURIOLI, 1997; HEREMANS; SMELLER, 1997). A formação de gel é o resultado da desnaturação parcial das cadeias laterais reativas dos grupos proteicos e da agregação proteica em dimensão de redes proteicas com estruturas menores (KEIM e HINRICHS, 2004).

A hipótese mais aceita para explicar o efeito da APH no favorecimento da dissociação proteica é a existência de espaços vazios no interior das proteínas, que se originam em decorrência da impossibilidade de que todos os resíduos de aminoácidos assumam os mínimos de distância intermoleculares possíveis. Quando a proteína se desenovela, o sistema proteína-solvente sofre contração de volume, devido ao "empacotamento" dos resíduos de aminoácidos pela molécula do solvente. Dessa forma, o que se supõe é que, sob pressão, a água infiltra a proteína, cujas ligações fracas são desestabilizadas (FOGUEL, 1993). De acordo com o princípio de Le Chatelier, a aplicação de pressão desloca o equilíbrio no sentido da diminuição do volume, ou seja, direcionando para o estado dissociado. Com exceção das pontes de hidrogênio e das ligações covalentes, todas as demais interações responsáveis por manter as proteínas em estado nativo são afetadas sob pressão. Esta variação de volume não promove alterações significativas na estrutura secundária das proteínas, pois esta é estabilizada por pontes de hidrogênio e por ligações covalentes (HEREMANS; SMELLER, 1997).

Yamamoto et al. (1992) realizaram estudos relacionados com a agregação de proteínas cárneas (miosina e metamioglobina) quando submetidas à $\mathrm{APH}$. Verificaram que moléculas de miosina não pressurizadas apresentaram-se como monômeros e com duas extremidades. Comparando-se com moléculas de miosina pressurizada, verificou-se que, a pressões acima de $140 \mathrm{MPa}$, ocorreram interações entre extremidades para formar oligômeros, alterações estas observadas através de microscopia eletrônica de transmissão. Com o aumento da pressão, os grupamentos se compactaram e aumentavam de tamanho. Mesmo depois de tratamento com pressão a $210 \mathrm{MPa}$, por 5 min, moléculas de miosina monoméricas eram ainda observadas, apesar da maior proporção resultante de moléculas de miosina com apenas uma extremidade ter aumentado. Verificaram, ainda, que tratamentos de até 210 MPa não induziam à geleificação e que o tratamento térmico da solução pressurizada resultou em gel, com rigidez e microestrutura similares ao formado somente com o tratamento térmico. Dessa maneira, os autores constataram que o tratamento com pressão, provavelmente, não afetou a estrutura helicoidal original da calda de monômeros da miosina. 
Messens et al. (1997) observaram que, em pressões acima de 300-400 MPa, ocorre perda da estrutura da proteína, actina e miosina foram desnaturadas, assim como muitas das proteínas sarcoplasmáticas. A mioglobina foi irreversivelmente desnaturada a pressões de $400 \mathrm{MPa}$.

Ma e Ledward (2004) verificaram que amostras de carne, após diferentes tratamentos de pressão (tempo e temperatura de pressurização constantes, de 20 min e $20^{\circ} \mathrm{C}$ ), apresentaram três picos em análises realizadas utilizando calorimetria diferencial de varredura (DSC). Os picos endotérmicos encontrados nas amostras não pressurizadas eram de miosina, colágeno e actina, e os maiores picos desses componentes foram obtidos a $54,6,67,1$ e $77,3^{\circ} \mathrm{C}$, respectivamente. Quando do tratamento a $200 \mathrm{MPa}$, houve um decréscimo nos picos de miosina e actina e, a $400 \mathrm{MPa}$ ou mais, os picos de actina desapareceram. Os autores observaram, ainda, que o pico de colágeno parece não ter sido afetado pelo tratamento de pressão. Suzuki et al. (1994) também observaram que o tratamento de pressão causou mudanças insignificantes no colágeno intramuscular das carnes analisadas. Estes resultados são similares aos encontrados por Angsupanich et al. (1999), para carne de peru.

A APH também induz a modificações na estrutura do sarcômero, em particular nas linhas Z e nas bandas $\mathrm{M}$ e I, que são similares àquelas obtidas nas miofibrilas pela ação da calpaína, e que a atividade global das calpaínas pode ser aumentada pelo tratamento à $\mathrm{APH}$. Ao verificar mudanças na actina, miosina e actomiosina após o tratamento com APH, foi observado que ocorreu despolimerização, ocasionando redução do volume da carne, acompanhada pela liberação de água (GHOSH et al., 2001 apud SLONGO, 2008).

Scheibenzuber et al. (2002 apud STEPHAN (2006), utilizando-se de microscopia eletrônica de varredura, estudaram o efeito da alta pressão nas mudanças microestruturais das proteínas de carne suína. Os autores utilizaram carnes tratadas de 100 a $600 \mathrm{MPa}$ por um tempo de 10 min e uma amostra controle não pressurizada. Observaram que a $100 \mathrm{MPa}$, ocorreu um "inchaço" do complexo actina/miosina, que atribuíram à desnaturação das proteínas miofibrilares ocasionada pela aplicação de pressão. Concluíram, ainda, que o inchamento do endomísio da carne suína também pode ser explicado pela desnaturação das proteínas fibrosas e que, durante o tratamento à alta pressão, a desnaturação das proteínas miofibrilares e sarcoplasmáticas inibe a expansão das miofibrilas até seu volume inicial, durante a descompressão. Sendo assim, como decorrência, o endomísio é dilatado durante a descompressão e preenche os espaços mais amplos entre as fibras musculares. Observaram, também, que a pressões acima de $300 \mathrm{MPa}$, ocorre a desnaturação das proteínas sarcoplasmáticas solúveis, e que essas mudanças estruturais levam à solidificação moderada da textura da carne. Resultados similares foram confirmados por Yamamoto et al. (1992).

Marcos et al. (2010) avaliaram o efeito combinado de pressão e temperatura, em condições ambientais controladas ou refrigeradas, sobre proteínas sarcoplasmáticas bovinas e parâmetros de qualidade. Utilizaram carne bovina (Longissimus dorsi) para pressurização em um intervalo de 200 a 600 MPa e entre 10 e $30{ }^{\circ} \mathrm{C}$ de temperatura, e observaram que o processo de alta pressão induziu a uma redução de solubilidade ( $p<0,001)$ em relação aos controles não tratados e, de forma mais pronunciada, acima de $200 \mathrm{MPa}$. Em pressões superiores a $200 \mathrm{MPa}$, induziu a uma elevada modificação na solubilidade $(p<0,001)$ e a uma redução da capacidade de retenção de água, demonstrando alteração significativa na composição da proteína sarcoplamática. A temperatura de pressurização afetou principalmente a solubilidade proteica.

\subsection{Efeito da alta pressão sobre as enzimas}

As pressões relativamente baixas ( 100 MPa) têm mostrado ativação de algumas enzimas e este efeito de estimulação é somente observado em enzimas monoméricas; tal fato deve-se possivelmente ao desnovelamento e à posterior reestruturação, levando à maior exposição do sítio ativo e ao incremento da atividade dessas enzimas (CURL et al. apud HENDRICKX et al., 1998; JOLIBERT et al. apud HENDRICKX et al., 1998). Pressões mais elevadas geralmente induzem à inativação enzimática (CURL et al. apud HENDRICKX et al., 1998). Essa inativação pode ocorrer em quatro grupos de enzimas, baseando-se na perda e na recuperação da atividade: i) inativação completa e irreversível; ii) inativação completa e reversível; iii) inativação incompleta e irreversível; e iv) inativação incompleta e reversível (HENDRICKX et al., 1998).

O amaciamento de carnes durante a observação post-mortem causada por alta pressão tem sido geralmente atribuído ao rompimento de proteínas miofibrilares por várias proteases endógenas, em particular pelas catepsinas (YAMAMOTO et al. 2007). Buckow et al. (2010) estudaram a atividade das proteases na carne utilizando um modelo de pressão e temperatura combinadas em um substrato modelo, e observaram que a aplicação de alta pressão tem o potencial de alterar a estabilidade e a atividade catalítica de catepsina D. Observaram que a inativação dessa enzima foi acelerada com aumento da pressão ou da temperatura, e seu maior ponto de maior estabilidade foi alcançado a $100 \mathrm{MPa}$, mesmo em altas temperaturas. A atividade catalítica da 
catepsina $\mathrm{D}$ aumentou com a temperatura, mas diminuiu drasticamente com a alta pressão.

Homma et al. (1995, 1996) estudaram os efeitos da pressurização hidrostática nas atividades das proteases dos complexos de calpaínas ( $\mu$-calpaína, m-calpaína e o inibidor calpastatina) e de catepsinas em carne de coelho. Os autores observaram que em carnes pressurizadas acima de $100 \mathrm{MPa}$, os níveis de calpaína apresentaram certa diminuição com o aumento da pressão e, a 300 MPa, os níveis de calpaína mostraram-se bastante reduzidos. As amostras controles e pressurizadas, obtidas a partir de extratos, foram submetidas à cromatografia líquida de alta eficiência (High Performance Liquide Chromatography - HPLC) e foi observado que calpaínas e calpastatina perderam suas atividades com um aumento crescente da pressão; porém, o grau de perda resultou diferente em cada enzima. Dessa forma, enquanto as calpaínas resistiram a alterações até a pressão de $200 \mathrm{MPa}$, as calpastatinas foram inativadas a $100 \mathrm{MPa}$. Verificaram, ainda, que a APH aumentou a liberação das catepsinas lisossomais e, como decorrência, houve o incremento de suas atividades no músculo, bem como o aumento das atividades das calpaínas pela liberação de $\mathrm{Ca}^{+2}$ do retículo sarcoplasmático, e a inativação de calpastatina. Assim, o aumento da atividade das calpaínas e catepsinas na carne pressurizada e a inativação de calpastatinas, conjuntamente verificados a $200 \mathrm{MPa}$, resultaram no amaciamento da carne. Resultados similares foram encontrados por Hugas et al. (2002), que observaram que carnes tratadas a $200 \mathrm{MPa}$ apresentavam inibição da ação da calpastatina; porém, nesse caso, somente a 400 MPa foi observada degradação da calpaína.

Jung et al. (2000a, 2000b) observaram um aumento significativo na atividade das enzimas lisossomais (catepsinas) na carne bovina (músculos Logissimus dorsi e Bíceps femoris) pressurizada a $520 \mathrm{MPa}$, o que foi mantido durante todo o processo de maturação. No entanto, tal incremento de atividade não refletiu na melhoria da maciez da carne ou em maior velocidade de maturação. A melhoria da maciez da carne foi atribuída a um conjunto de modificações no estado de contração e modificações acentuadas nos componentes miofibrilares a partir da aplicação da pressão, resultando ainda em maior perda por cozimento. Em outro estudo, trabalhando com os mesmos cortes de carne, porém com pressões variando entre 100 e $600 \mathrm{MPa}$, os mesmos autores verificaram que a alta pressão causa modificações na estrutura miofibrilar e que essas são dependentes do nível de pressão utilizada no tratamento, sendo que modificações relevantes são encontradas somente quando utilizadas pressões acima de $300 \mathrm{MPa}$.

\subsection{Efeito da alta pressão sobre a cor da carne}

Carlez et al. (1995) investigaram os efeitos da alta pressão na cor e no conteúdo de mioglobina de carne moída embalada a vácuo. Eles notaram uma cor rósea na carne tratada a 200-350 MPa, a qual se tornou marrom acinzentada a 400-500 MPa. Quer dizer, houve um decréscimo no conteúdo de mioglobina a 200-500 MPa, uma redução na oximioglobina e um aumento na metamioglobina a 400-500 MPa. Os autores sugeriram que a descoloração da carne durante a alta pressão é devida ao efeito clareador a 200-300 MPa causado pela desnaturação da globina, pela liberação do grupamento heme ou pela oxidação do ferro da mioglobina a $400 \mathrm{MPa}$. Estes autores concluíram que a perda de cor da carne bovina submetida à $\mathrm{APH}$ é um fenômeno complexo e que pressões em torno de $200 \mathrm{MPa}$ provocam efeito branqueador, quando a coloração rosada torna-se mais pálida. Simultaneamente, verificaram que os valores de $L^{*}$, notadamente, aumentaram.

Shigehisa et al. (1991) encontraram mudanças similares nos valores de $L^{*}$ e $a^{*}$ em carne suína pressurizada. Os valores de $L^{*}$ começaram a aumentar em pressões entre 100 e $200 \mathrm{MPa}$, alcançando um valor máximo em pressões entre 300 e $400 \mathrm{MPa}$. Verificaram que, acima de $600 \mathrm{MPa}$, não houve nenhuma alteração. Os autores verificaram que um decréscimo moderado nos valores de $a^{*}$ ocorreu em pressões entre 100 e $200 \mathrm{MPa}$, progredindo até $600 \mathrm{MPa}$, e relataram que nenhuma explicação era determinada para estes fenômenos.

Jung et al. (2003), estudando os efeitos da alta pressão sobre a cor da carne bovina (músculo Bíceps femoris) e empregando pressões variando de 50-600 MPa a $10{ }^{\circ} \mathrm{C}$, observaram alterações nos parâmetros 'cor total' e 'metamioglobina' a pressões acima de $300 \mathrm{MPa}$. Os valores de metamioglobina são aumentados com o aumento da intensidade da pressão, provocando diminuição da cor vermelha na carne, o que é acompanhado por um aumento na diferença total de cor, em relação à carne não tratada.

McArdle et al. (2010) estudaram os efeitos combinados do tratamento de alta pressão e da temperatura na carne bovina (Pectoralis profundus), utilizando pressões de 200, 300 e $400 \mathrm{MPa}$ a duas diferentes temperaturas $\left(20\right.$ e $\left.40^{\circ} \mathrm{C}\right)$, e concluíram que a pressurização a $200 \mathrm{MPa}$ teve um menor impacto sobre os parâmetros de cor do que pressões maiores. 0 processamento à alta pressão teve um efeito significativo sobre os parâmetros de cor $\left(L^{*}, a^{*}, b^{*}\right)$, sendo que, com exceção do tratamento a $200 \mathrm{MPa}$ a $20{ }^{\circ} \mathrm{C}$, todas as demais condições resultaram em um aumento no valor de L* (luminosidade), associado ao "embranquecimento/ perda de brilho" atribuído à desnaturação da globina, ao deslocamento heme ou à liberação e à oxidação de íons ferrosos. Marcos et al. (2010), trabalhando com carne bovina (Longissimus dorsi) e utilizando pressões variando de 200-600 MPa, encontraram resultados semelhantes, observando que em amostras pressurizadas a pressões 
acima de $200 \mathrm{MPa}$, ocorreram alterações relevantes na cor.

\subsection{Efeito da alta pressão sobre os lipídios e a oxidação lipídica}

Tuboly et al. (2003) avaliaram o efeito da APH em carne mecanicamente separada de peru, considerando duas condições de armazenamento: em um tratamento, a carne foi submetida a uma pressão de 200 MPa por 20 min e, em seguida, armazenada por 15 dias sob refrigeração; e em outro tratamento, foi aplicada uma pressão de 400 MPa por 20 min, sendo a carne congelada $\left(-20{ }^{\circ} \mathrm{C}\right)$ e armazenada por oito meses. Os produtos foram submetidos a análises de oxidação de lipídios (TBARS) e oxidação de colesterol. Observou-se aumento nos valores de TBARS, bem como formação de compostos de oxidação do colesterol nos dois produtos, em comparação com o controle.

Cheah e Ledward (1996), avaliando a aplicação de $\mathrm{APH}$ até $200 \mathrm{MPa}$ em carne de suíno, não observaram o aumento da oxidação lipídica (índice de TBARS), por um período de quatro dias, estocada a $4{ }^{\circ} \mathrm{C}$; entretanto, verificaram aumento acentuado nos valores de TBARS quando aplicada pressão de $400 \mathrm{MPa}$ ou maior. Quando essa carne sofreu tratamento térmico associado à alta pressão, o valor de TBARS também aumentou. Através de espectrometria de reflectância, foi verificado que o aumento de pressão nestes tratamentos ocasionou a oxidação da oximioglobina para metamioglobina, sendo constatado este fenômeno através do desaparecimento do pico de oximioglobina, quando maiores pressões forem aplicadas. E através de calorimetria diferencial de varredura (DSC), foi verificada a desnaturação da miosina e da actina em diferentes pressões aplicadas. Constatou-se que o efeito catalítico da alta pressão aumentou com a pressão até que as proteínas eram desnaturadas, isto porque os tecidos são rompidos e a quebra da mioglobina e da hemoglobina libera ferro, que catalisa a oxidação. Quando foi utilizado o tratamento com pressão a $400 \mathrm{MPa}$ ou mais, o espectro de reflectância da carne pareceu como o da carne cozida; e, na carne cozida, o pigmento está, provavelmente, na forma hemoproteica férrica desnaturada, o que pode acelerar a oxidação lipídica.

Ma et al. (2007) relataram aumento de valores de TBARS em carne bovina (Longissimus dorsi) tratada com pressões iguais ou maiores a $400 \mathrm{MPa}$, a $20 \mathrm{e}$ $40{ }^{\circ} \mathrm{C}$. Esses resultados confirmam aqueles verificados em estudos anteriores e demonstram que, a pressões elevadas ( $\geq 400 \mathrm{MPa}$ ), o processamento provoca redução da estabilidade oxidativa da carne (CHEAH e LEDWARD, 1996).

McArdle et al. (2010), considerando efeitos combinados de alta pressão (200 a $400 \mathrm{MPa}$ ) e temperatura $\left(20\right.$ e $40^{\circ} \mathrm{C}$ ) na carne bovina (Pectoralis profundus), observaram aumento nos valores de TBARS nas pressões mais elevadas (300 e $400 \mathrm{MPa}$ ). Apesar de tais alterações serem observadas a pressões mais elevadas, não foram verificadas alterações nas relações ácidos graxos poli-insaturados/ácidos graxos saturados (AGPI/AGS) ou ômega 6/ômega 3. Conjuntamente, esses resultados demonstram que tratamentos com pressões moderadas (200 MPa) afetam minimamente os parâmetros de qualidade da carne.

\subsection{Efeito da alta pressão sobre a maciez da carne}

Existe um consenso em estudos com consumidores que a maciez é o fator mais importante entre todos os atributos de qualidade que caracterizam o consumo de carne (JUNG et al.,2000, 2000a; DENOYELLEA e LEBIHAN, 2003). Recentemente, tem sido publicado um grande número de trabalhos a respeito da aceleração do amaciamento por maturação de carne acondicionada, durante o processo, que resulta de mudanças ocorridas na estrutura das miofibrilas causadas pela alta pressão (MACFARLANE, 1985; KENNICK et al., 1980; RIFFERO e HOLMES, 1983; LOCKER e WILD, 1984; SUZUKI et al., 1990, 1992; CHEFTEL e CULIOLI, 1997).

O tratamento de alta pressão é uma técnica que tem sido apenas mais recentemente estudada para amaciamento de carne in natura. Segundo Solomon et al. (2006), o processo de APH mostrou-se adequado para aumentar a maciez de vários cortes de carne. Quando comparado à maturação convencional para amaciamento, o APH resultou mais efetivo, propiciando redução em torno de $23 \%$ na força de cisalhamento, determinada pelo método de Warner Bratzler Shear Force (WBSF), mesmo em tempos mais prolongados de maturação: 0 dia (6,33 versus 8,17 kgf), 5 dias (5,06 versus 6,60 kgf) e 8 dias $(4,52$ versus $5,82 \mathrm{kgf})$. Foram encontrados valores significativamente maiores ( $p<0,001)$ para fragmentação miofibrilar no processo com APH quando comparado com os demais tratamentos, independentemente do número de dias de maturação.

Ma e Ledward (2004), processando carne bovina e utilizando pressões de 0.1 a $800 \mathrm{MPa}$, encontraram melhoria na maciez em pressão de $200 \mathrm{MPa}$; porém, em contrapartida, houve uma diminuição da maciez da carne em amostras pressurizadas acima de $400 \mathrm{MPa}$

Segundo Sun e Holley (2010), os efeitos da alta pressão na maciez ou na maturação de carnes são dependentes da fase de rigor mortis, pressão, temperatura e sua combinação. Normalmente, tratamentos com pressões mais baixas (<200 MPa) podem amaciar carnes em fase pré-rigor mortis, enquanto em carnes em fase pós-rigor mortis, o amaciamento com alta pressão só pode ser alcançado em temperaturas mais elevadas $(40 \mathrm{a}$ $\left.80^{\circ} \mathrm{C}\right)$. Isso ocorre principalmente pela desnaturação, por 
alta pressão, das estruturas miofibrilares na fase pré-rigor e pela necessidade de temperaturas elevadas na fase pós-rigor, para que ocorra a gelatinização das estruturas de tecido conjuntivo; note-se, ainda, que temperaturas elevadas podem causar modificações na cor, o que no comércio de carne in natura não é desejável.

Sikes et al. (2010) compararam a textura de carne bovina post-rigor (Sternomandibularis) cozida a $60{ }^{\circ} \mathrm{C}$ por 20 min, submetida ou não a tratamento a $200 \mathrm{MPa}$, antes do cozimento. As análises de textura apontaram uma melhora significativa na maciez decorrente da pressurização prévia, com base em valores de força máxima, reduzindo em $49 \mathrm{~N}$ o pico máximo da força de cisalhamento obtida pelo método de Warner Bratzler Shear Force.

\section{Conclusões}

O processo de alta pressão vem sendo utilizado industrialmente em diferentes setores da indústria de alimentos, em diversos países e de forma gradualmente crescente, a despeito de ser uma tecnologia relativamente recente. Além de propiciar a descontaminação e a preservação, tal processo possui a vantagem de manter as características originais desejáveis na maioria dos alimentos ou até de promover pequenas alterações sensoriais desejáveis ao consumidor. Mais recentemente, sua aplicação potencial no processamento de carne bovina in natura tem sido estudada. O principal método comumente utilizado para amaciamento de carnes (maturação) apresenta elevada demanda de energia, resultando em um processo bastante prolongado, com duração de vários dias, acarretando custos operacionais elevados com comprometimento de capital de giro, além da necessidade de investimentos em construções físicas. A APH, por outro lado, possibilita um tempo de processo bastante curto, além do possível aumento na validade comercial pela redução da carga microbiana. Processamentos com pressões variando entre 100 e $300 \mathrm{MPa}$ são sugeridos na literatura como ideais para carne in natura, tendo em vista que utilizando pressões superiores a $400 \mathrm{MPa}$ acarretam-se alterações indesejáveis na cor e na textura (diminuição do amaciamento) da carne, e aumento da oxidação lipídica. O uso do tratamento com APH de carne resfriada desossada a quente, para evitar encurtamento causado pelo rigor, pelo frio e pelo descongelamento parece ser uma linha interessante para novos estudos.

O investimento para implantação da tecnologia, relacionado ao custo do equipamento, ainda é elevado, porém tem decrescido com a evolução tecnológica e a perspectiva de aumento de escala de produção. Tal perspectiva deverá facilitar a obtenção de produtos com qualidade superior, sem aumento elevado do preço para o consumidor.
Além desses aspectos, a APH é considerada uma tecnologia limpa, com baixa demanda energética ou necessidade de outros insumos ou utilitários (como água para o processamento), e sem geração de resíduos ou efluentes pelo processo em si. Propicia, assim, menor impacto ambiental, contribuindo para ampliar os já elevados volumes de exportação, em alinhamento com mercados internacionais, de elevada exigência de segurança e qualidade dos produtos, e sustentabilidade de produção. Sua aplicação futura no amaciamento de carne in natura pode possivelmente colaborar para o incremento da qualidade do produto nacional, tornando ainda mais competitiva a indústria brasileira em nivel mundial, com perspectivas de consolidação e ampliação de liderança. Outros estudos, delineados a partir dos resultados compilados e discutidos nesta revisão, são necessários para ampliação da compreensão dos aspectos técnico-científicos relacionados à sua utilização e à ampliação do estado da técnica, e de sua aplicação tecnológica.

\section{Referências}

ANGSUPANICH, K.; EDDE, M.; LEDWARD, D. A. Effects of high pressure on the myofibrillar proteins of cod and turkey muscle. Journal of Agricultural and Food Chemistry, Washington, v. 47, n. 1, p. 92-99, 1999. PMid:10563855. http://dx.doi.org/10.1021/ jf980587p

ANSTINE, T. T. High pressure processing for safe, quality foods. Cereal Food World, Minneapolis, v. 48, n. 1, p. 5-8, 2003.

BARBOSA-CÁNOVAS, G. V.; RODRÍGUEZ, J. J. Update on nontheral food processing technologies, irradiation and ultrasound. Food Australia, Australia, v. 54, p. 11, 2002.

BOWKER, A. C.; FAHRENHOLZ, T.; PAROCZAY, E. W.; SOLOMON, M. B. Influence of Hydrodynamic Pressure Processing and Aging on Tenderness and Muscle Proteins in Beef Strip Loins [abstract]. American Meat Science Association Reciprocal Meat Conference Proceedings, Champaign, Illinois, n. 52, p. 18-21, 2006.

BRIDGMAN, P. W. The coagulation of albumen by pressure. Journal of Biological Chemistry, Maryland, v. 19, p. 511-512, 1914.

BUCKOW, R.; TRUONG, B. Q.; VERSTEEG, C. Bovine cathepsin $D$ activity under high pressure. Food Chemistry, Oxford, v. 120 , n. 2, p. $474-481,2010$. http://dx.doi.org/10.1016/j. foodchem.2009.10.040

BUTZ, P.; TAUSCHER, B. Emerging Technologies: chemical aspects. Food Research International, Oxford, v. 35, n. 2-3, p. 279-284, 2002. http://dx.doi.org/10.1016/S0963-9969(01)00197-1

CARLEZ, A.; VECIANA-NOGUES, T.; CHEFTEL, J. C. Changes in colour and myoglobin of minced beef meat due to high pressure processing. Lebensmittel-Wissenschaft und-Technologie, Kidlington, v. 28, n. 5, p. 528-538, 1995. 
Revisão: Modificações físico-químicas na carne in natura bovina decorrentes da alta pressão hidrostática CABRAL NETO, O. et al.

CHEAH, P. B.; LEDWARD, D. A. High pressure effects on lipid oxidation in minced pork. Meat Science, Oxford, v. 43, n. 2, p. 123-134, 1996. http://dx.doi.org/10.1016/03091740(96)84584-0

CHEFTEL, J. C. Review: high-pressure, microbial inactivation and food preservation. Food Science and Technology International, California, v. 1, n. 2-3, p. 75-90, 1995. http://dx.doi. org/10.1177/108201329500100203

CHEFTEL, J.; CURIOLI, J. Effects of high pressure on meat: a review. Meat Science, Oxford, v. 46, n. 3, p. 211-236, 1997. http:// dx.doi.org/10.1016/S0309-1740(97)00017-X

DENOYELLEA, C.; LEBIHAN, E. Intramuscular variation in beef tenderness. Meat Science. Oxford, v. 66,n. 1, p. 241-247. 2003.

FARKAS, D. F.; HOOVER, D. G. High pressure processing. Journal of Food Science, Chicago, supl., p. 47-64, 2000.

FOGUEL, D. Efeito da Alta Pressão Hidrostática e Baixas Temperaturas em Organismos e Estruturas Fotossintéticas. 1993. Tese (Doutorado em Bioquímica)-Universidade Federal do Rio de Janeiro, Rio de janeiro, 1993.

FOOD AND AGRICULTURE ORGANIZATION - FAO. Technical Elements of New and Emerging Non-Thermal Food Technologies. 2001. Disponível em: <http://www.fao.org/ag/ags/ agsi/Nonthermal/nonthermal_1.htm\#_>. Acesso em: 10 abr. 2010.

FOOD AND DRUG ADMINISTRATION - FDA. Center For Food Safety And Applied Nutrition. Kinetics of microbial inactivation for alternative food processing technologies. High Pressure Processing. 2000. Disponível em: <http://www.cfsan.fda. gov/ comm/ift-hpp.html>. Acesso em: 10 abr. 2010.

GARCIA, A. F.; BUTZ, P.; TAUSCHER, B. Under Pressure. Food Manufacture, London, v. 67, p. 23-24, 1992.

HAYASHI, R. Application of High Pressure to Food Processing and Preservation: Philosophy and Development, Engineering and Food. London: Elsevier Applied Science, 1989. p. 815. vol. 2.

HENDRICKX, M.; LUDIKHUYZE, L.; VAN den BROECK, I.; WEEMAES, C. Effects of High pressure on enzimes related to food quality (review). Food Science \& Technology, Oxfod, v. 9 , n. 5, p. 197-203, 1998.

HEREMANS, K.; SMELLER, L. Review: Protein structure and dynamic at high pressure. Biochimica et Biophysica Acta, Oxford, v. 1386, n. 2, p. 353-370, 1997.

HITE, B. H. The effect of pressure on the preservation of milk. West Virginia Agricultural Experimental Station Bulletin, Morgantown, v. 58, p. 15-35, 1899.

HOMMA, N.; IKEUCHI, Y.; SUZUKI, A. Levels of calpain and calpastatin in meat subjected to high pressure. Meat Science, Oxford, v. 41, n. 3, p. 251-260, 1995. http://dx.doi. org/10.1016/0309-1740(95)00005-6

HOMMA, N.; IKEUCHI, Y.; SUZUKI, A. Effects of high pressure treatment on proteolytic system in meat. Progress in Biotechnology, Oxford, v. 13, p. 327-330, 1996. http://dx.doi. org/10.1016/S0921-0423(06)80054-7
HUGAS, M.; GARRIGA, M.; MONFORT, J. M. New mild technologies in meat processing: high pressure as a model technology. Meat Science, Oxford, v. 62, n. 3, p. 359-371, 2002. http://dx.doi.org/10.1016/S0309-1740(02)00122-5

INSTITUTO BRASILEIRO DE GEOGRAFIA E ESTATÍSTICA - IBGE. Disponível em: <http://www.sidra.ibge.gov.br>. Acesso em: 10 mar. 2010.

JUNG, S.; LAMBLLERIE-ANTON, M.; GHOUL, M. Textural changes in bovine meat treated with high pressure. High Pressure Research, New York, v. 19, n. 1-6, p. 69-74. 2000.

JUNG, S.; GHOUL, M.; LAMBLLERIE-ANTON, M. Change in lysosomal enzyme activities and shear values of high pressure treated meat during ageing. Meat Science, Oxford, v. 56, n. 3, p. 239-246, 2000a. http://dx.doi.org/10.1016/S03091740(00)00048-6

JUNG, S.; GHOUL, M.; LAMBLLERIE-ANTON, M. Modifications of ultrastructure and miofibrilar proteins of post-rigor beef treated by high pressure. Lebensmittel-Wissenschaft und-Technologie, Kidlington, v. 33, n. 4 , p. 313-319, 2000b.

JUNG, S.; GHOUL, M.; LAMBLLERIE-ANTON, M. Influence of high pressures on the color and microbial quality of beef meat. Lebensmittel-Wissenschaft und-Technologie, Kidlington, v. 36, n. 6, p. 625-631, 2003.

KEIM, S.; HINRICHS, J. Influence of stabilizing bonds on the texture properties of high pressure induced whey protein gels. International Dairy Journal, Oxford, v. 14, n. 4, p. 355-363, 2004. http://dx.doi.org/10.1016/j.idairyj.2003.10.010

KENNICK, W. H.; ELGASIM, E. A.; HOLMES, Z. A.; MEYER, P. F. The effect of pressurization of pre-rigor muscle on post-rigor meat characteristics. Meat Science, Oxford, v. 4, n. 1, p. 33-40, 1980. http://dx.doi.org/10.1016/0309-1740(80)90021-2

LOCKER, R. H.; WILD, D. J. C. Tenderization of meat by pressureheat involves weakening of the gap filaments in myofribrils. Meat Science, Oxford, v. 10, n. 3, p. 207-233, 1984. http://dx.doi. org/10.1016/0309-1740(84)90023-8

MA, H. J.; LEDWARD, D. A. High pressure/thermal treatment effects on the texture of beef muscle. Meat Science, Oxford, v. 68 , n.3, p. 347-355, 2004. http://dx.doi.org/10.1016/j. meatsci.2004.04.001

MA, H. J.; LEDWARD, D. A.; ZAMRI, A. I.; FRASIER, R. A.; ZHOU, G. H. Effects of high pressure/thermal treatment on lipid oxidation in beef \& chicken muscle. Food Chemistry, Oxford, v. 104, n. 4, p.1575-1579, 2007. http://dx.doi.org/10.1016/j. foodchem.2007.03.006

McARDLE, R.; MARCO, B.; KERRY, J. P.; MULLEN, A. Monitoring the effects of high pressure processing and temperature on selected beef quality attributes. Meat Science, Oxford, v. 86, n. 3, p. 629-634, 2010. PMid:20708343. http://dx.doi.org/10.1016/j. meatsci.2010.05.001

MacFARLANE, J. J.High pressure technology and meat quality. In: Lawine, R. A. (Ed.). Developments in Meat Science. London: Elsevier Applied Science. 1985. p 155-84. vol. 3. 
Revisão: Modificações físico-químicas na carne in natura bovina decorrentes da alta pressão hidrostática CABRAL NETO, O. et al.

MARCOS, B.; KERRY, J. P.; MULLEN, A. M. High pressure induced change on sarcoplasmic protein fraction and quality indicators. Meat Science, Oxford, v. 85, n. 1, p. 115-120, 2010. PMid:20374874. http://dx.doi.org/10.1016/j.meatsci.2009.12.014 MERTENS, B.; DEPLACE, G. Engineering aspects of highpressure technology in food industry. Food Technology, Chicago, v. 47, p. 164-169, 1993.

MESSENS, W.; VAN CAMP, J.; HUYGHEBAERT, A. The use of high pressure to modify the functionality of food proteins. Trends in Food Science \& Technology, Oxford, v. 8, n. 4, p. 107-112, 1997.

MEYER, R. S.; COOPER, K. L.; KNORR, D.; LELIEVELD, H. L. M. High pressure sterilization of foods. Food Technology, Chicago, v.54, n. 11, p.67-72, 2000.

ORGANIZAÇÃO MUNDIAL DO COMÉRCIO - OMC. Economic Research and Analysis. 2007. Disponivel em: <http://www.wto. org/english/res_e/reser_e/reser_e.htm>. Acesso em: 10 jan. 2010.

PALMIERI, L. C. Estudo do Enovelamento e Agregação do Monômero da Proteína Amiloidogênica Transtirretina (M-TTR). 2005. Dissertação (Mestrado em Química Biológica)Universidade Federal do Rio de Janeiro, Rio de janeiro, 2005.

PATERSON, M. F. Microbiology of pressure treated foods. Journal of Applied Microbiology, Malden, v. 98, n. 6, p. 1400-1409, 2005. PMid:15916652. http://dx.doi.org/10.1111/j.13652672.2005.02564.x

PELLIETIER, B. High pressure treatment for fruit juice. New solutions for low-cost high pressure processing of fruit juice. Fruit Processing, Strassenhaus, v. 6, p. 216-217, 2001.

RASTOGI, N. K.; RAGHAVARAO, K. S. M. S.; BRAMASUBRAMANIAM, V.M.; NIRANJAN, K.; KNORR, D. Opportunities and challenges in high pressure processing of foods. Critical Review Food Science and Nutrition, v. 47, n. 1, p. 69-112, 2008.

RIFFERO, L. M., HOLMES, Z. A. Characteristics of pre-rigor pressurized versus conventionally processed beef cooked by microwave and by boiling. Journal of Food Science, Malden, $v$. 48, n. 2, p. 346-350,372, 1983.

ROVERE, P. The third dimension of food technology. Tecnologie Alimentari Sistemi per Produrre, v. 4, p. 2-8, 1995.

SIKES, A.; TORMBERG, E.; TUME, R. A proposed mechanism of tenderising post-rigor beef using high pressure-heat treatment. Meat Science, Oxford, v. 84, n. 3, p. 390-399, 2010. PMid:20374801. http://dx.doi.org/10.1016/j.meatsci.2009.09.007

SOLOMON, M. B.; LIU, M.; PATEL, J. R.; BOWKER, A. C.; SHARMA, M. Processo de Pressão hidrodinâmico para Melhorar Qualidade de Carne e Segurança. In: NOLLET, L. M. L.; TOLDRA, F. (Eds.). Tecnologias Avançadas para Processo de Carne. Boca Raton, FL: CRC Press, Taylor \& Francis Grupo, 2006. p. 219-244.

SHIGEHISA, T.; OHMORI, T.; SAITO, A.; TAJI, S.; HAYASHI, R. Effects of high hydrostatic pressure on characteristics of pork slurries and inactivation of microorganisms associated with meat and meat products. International Journal of Food
Microbiology. Oxford, v. 12, n. 2-3, p. 207-216, 1991. http://dx. doi. org/10.1016/0168-1605(91)90071-V

SLONGO, A. P. Determinação da Vida de Prateleira e Análise Sensorial de Presunto Suíno Submetido ao Tratamento de Alta Pressão Hidrstática. 2008. 163 f. Tese (Doutorado em Engenharia de Alimentos)- Universidade Federal de Santa Catarina, Santa Catarina, 2008.

STEPHAN, M. P.;SLONGO, A. P.; DELIZA, R., ROSENTHAL, A. Adaptação de método de extração e caracterização das proteínas extraídas de presunto submetido à alta pressão. Comunicado Técnico da Embrapa-CTAA,v. 96, p. 1-3, 2006.

SUN, X. D.; HOLLEY, R. A. High hydrostatic pressure effects on the texture of meats and meats products. Journal of Food Science, Malden, v. 75, n. 1, p. R17-R23, 2010. PMid:20492191. http://dx.doi.org/10.1111/j.1750-3841.2009.01449.x

SUZUKI, A.; HOMMA, N.; FUKUDA, A.; HIRAO, K.; URYU, T.; IKEUCHI, Y. Effects of high pressure treatment on the flavorrelated components in meat. Meat Science, Oxford, v. 37, n. 3, p. 369-379, 1994.

SUZUKI, A.; KIM, K.; HOMMA, N.; IKEUCHI Y.; SAITO, M. Acceleration of meat conditioning by high pressure treatment. High Pressure and Bioscience. Montrouge, France: Colloques Inserm/John Libbey Eurotext, 1992. p. 219-222. http://dx.doi. org/10.1016/0309-1740(94)90053-1

SUZUKI, A.; WATANABE, M.; IWAMURA, K.; IKEUCHI, Y.; SAITO, $M$. Effects of high pressure treatment on the ultrastructure and myofibrillar protein of beef skeletal muscle. Agricultural and Biological Chemistry, Tokyo, v. 54, n. 12, p. 3085-91. 1990.

TUBOLY, E.; LEBOVICS, V. K.; GAÁL, O.; MÉSZAROS, L.; FARKAS, J. Microbiological and lipid oxidation studies on mechanically deboned turkey meat treated by high hydrostatic pressure. Journal of Food Engineering, Oxford, v. 56, n. 2-3, p. 241-244, 2003. http://dx.doi.org/10.1016/S0260-8774(02)00260-1

VARDAG,T.; DIERKES, H.; KONER, P. High pressure food processing. Food Tech Europe, Hackensack, v. 3, n. 2, p. 106-110, 1995.

WILLIANS, A. New Technologies in Food Preservation and Processing: Part II. Nutrition \& Food Science, Sunnyvale, v. 1, p. 20-23, 1994.

YAMAMOTO, K.; MIURA, T.; YASUI, T. Gelation of myosin filament under high hydrostatic pressure. Food Structure, Chicago, v. 9 , p. 269-277, 1992.

YAMAMOTO, S.; NISHIUMI, T.; SUZUKI, A. Proteasome extracted from pressurized and aged skeletal muscles. In: ABE, F.; SUZUKI, A. (Eds.). Fourth International Conference on High Pressure Bioscience and Biotechnology. Japan, JStage: Tsukuba, 2007.

ZIMMERMAM, F.; BERGMAN, C. Isostatic high-pressure equipment for food preservation. Food Technology, Chicago, v. 47, n. 6, p. 162-163, 1993. 